\title{
Safety and Efficacy of Mechanical Thrombectomy with Solitaire Stent Retrieval for Acute Ischemic Stroke: A Systematic Review
}

\author{
Jun Seok Koh, MD', Sun Joo Lee, MD', Chang-Woo Ryu, MD², Ho Sung Kim, MD³
}

Purpose: In recent years, mechanical thrombectomy using Solitaire stent retrieval has been tried for treating acute ischemic stroke with a large artery occlusion. We systematically reviewed published articles to appraise the evidence that supports the safety and efficacy of the mechanical thrombectomy in acute strokes with Solitaire stent.

Materials and Methods: Systematic searches using Medline and Scopus were performed for studies evaluating mechanical thrombectomy using a Solitaire stent in acute ischemic stroke. Articles were included if they were published since 2008, contained at least 5 subjects, and provided clinical results.

Results: Thirteen articles ( 262 cases) were included in this review. The mean time of the procedures ranged from 37 to 95.6 minutes in 10 studies. The success of recanalization was achieved in $89.7 \%$ and the recanalization rate varied from $66.7 \%$ to $100 \%$ in all 13 studies. The overall rates of the symptomatic hemorrhagic complications and mortality were $6.8 \%$ and $11.1 \%$, respectively. A favorable outcome of mRS 2 or under was $47.3 \%$. Procedure-induced complications developed in $3.4 \%$.

Conclusion: The present review suggested that mechanical thrombectomy using a Solitaire stent in acute ischemic stroke was effective in recanalizing the occluded artery. The rate of procedural complications was small.

Key Words : Stroke; Mechanical recanalization; Self-expanding stent; Solitaire; Systematic review

${ }^{1}$ Departments of Neurosurgery and ${ }^{2}$ Radiology, Kyung Hee University Hospital at Gangdong, Seoul, Korea

${ }^{3}$ Department of Radiology, University of Ulsan, College of Medicine, Asan Medical Center, Seoul, Korea

Received December 5, 2011;

accepted after revision January 18, 2012.

Correspondence to: Jun Seok Koh, MD, Department of Neurosurgery, Kyung Hee University Hospital at Gangdong, 892 Dongnam-ro, Sangil-dong, Gangdong-gu, Seoul 134-090, Korea.

Tel. 82.2.440.6145 Fax. 82.2.440.7171

E-mail: gjs@khnmc.or.kr

This is an Open Access article distributed under the terms of the Creative Commons Attribution Non-Commercial License (http://creativecommons.org/licenses/by-nc/3.0) which permits unrestricted non-commercial use, distribution, and reproduction in any medium, provided the original work is properly cited.
The current goal in treating an acute ischemic stroke is to reopen the occluded vessels for regional reperfusion and salvage of threatened tissues. An intravenous administration of recombinant tissue plasminogen activator (rt-PA) was established to improve effectively neurological outcomes after an acute stroke. Unfortunately, intravenous thrombolysis is available within a period of fewer than 3 or 4.5 hours, or has contraindications, such as recent surgery. Another disadvantage of intravenous thrombolysis is that the recanalization rate is less than 50\% [1]. The ProUrokinase for Acute Cerebral Thromboembolism II (PROACT-II) trial randomized patients to either an intra-arterial delivery of recombinant pro-urokinase or 


\section{Jun Seok Koh, et al.}

control, after a middle cerebral artery thrombus has demonstrated that intra-arterial thrombolysis could offer benefits when applied to all patients with acute ischemic stroke [2]. Intra-arterial thrombolysis provides several advantages over the intravenous route by allowing a direct infusion of the thrombolytic agent into the thrombus, a longer time window of administration, and a higher recanalization rate. However, brain hemorrhage related to an administrated fibrinolytic agent can worsen the outcome of patients. Today, the achievement of recanalizing an occluded artery is a persistent challenge in the neurointerventional field. Much work has been focused on the endovascular mechanical thrombectomy because of its advantages over pharmacologic thrombolysis, including a rapid achievement of recanalization and enhanced efficacy in hemorrhagic events.

Since intra-arterial thrombolysis were proven by PROACT II trials in 1999, there has been many efforts to recanalize the occluded artery by endovascular methods, and novel devices that can easily approach intracranial arteries has leaded the use of devices for the thrombectomy of occluded intracranial arteries. Recently, the U.S. Food and Drug Administration (FDA) approved 2 neurothrombectomy devices as a endovascular device for restoring blood flow in patients experiencing an acute stroke who are otherwise ineligible for intravenous rt-PA, or for whom intravenous rt-PA has failed: the MERCI Retriever ${ }^{\circledR}$ (Concentric Medical, Mountain View, CA, U.S.A.) and the Penumbra System (Penumbra, Alameda, CA, U.S.A.). Several prospective clinical trials have supported the benefits and safety of these devices. Apart from these two devices, various techniques with off-label devices, including balloon angioplasty, thrombus fragmentation, aspiration, and thrombectomy have been reported to recanalize large arteries. Especially, there is a growing concern for the use of the stent in recanalizing the occluded artery. One of the recanalization techniques with the stent is the thrombectomy by retrieval of a self-expanding stent. The Solitaire neurovascular remodeling device (ev3 Inc, Irvine, CA, U.S.A.) that received the CE mark for the treatment of neurovascular diseases in 2007 was initially designed for aneurysm neck remodeling. This stent has a characterization that is fully retrievable and can be applied repeatedly. Thus, this stent can be used as a temporary recanalization with an enhancing effect of thrombolytic agent or it can pull the thrombus captured between the strut out of the body. The merit of the stent retrieval is that it can be applied repeatedly, it is accessible to small arteries, and there is no need for anticoagulation therapy. Unfortunately, despite several reports that have presented the application of the Solitaire stent to thrombectomy in acute stroke, there is scant evidence to back this up. Therefore, a critical evaluation of the current evidence is needed to assess the safety and efficacy of the mechanical thrombectomy using the Solitaire stent retrieval.

The objective of this review was to appraise the evidence that supports the safety and efficacy of the mechanical thrombectomy using a Solitaire stent retrieval in acute stroke.

\section{MATERIALS AND METHODS}

The principal goals were to review the clinical results, safety, and technical aspects regarding mechanical thrombectomy in the treatment of ischemic stroke using Solitaire stent retrieval. Our primary search began with a review of English language citations since 2008 using Medline and Scopus. The free-text search terms, "stroke", "infarction", "mechanical thrombectomy", "Solitaire", "mechanical recanalization", "clot retrieval", "stent recanalization", and "retrievable stent" were used in combination with Boolean operators AND or OR. Two reviewers independently screened titles and abstracts to identify potentially relevant articles. We included studies of any research design, such as case series, prospective trials, and retrospective observations, all of which contained at least 5 subjects and a specified reporting system of clinical results (i.e., Recanalization and modified Rankins score (mRS)). Studies that included not only thrombectomy using Solitaire stent retrieval but also other recanalization methods were included if the data were reported separately for each intervention. The studies were limited to those conducted on human subjects. Studies that reported a Solitaire stent was not used with the aim of arterial recanalization in treating acute stroke, use of another clot retrieval device, or review articles were excluded. When multiple articles drew on the same datasets, data were abstracted only once from the most comprehensive available report.

Data were collected for each study, including raw numbers plus any summary measures with standard deviations or ranges. Using a predesigned data extraction form, data extraction was performed based on the following: patient characteristics (sample size, age, sex, National Institutes of Health Stroke Scale (NIHSS) before procedure, affected artery, the presence of a tandem lesion); inclusion criteria for mechanical 
thrombectomy (time window, radiologic screening tool, time criteria for intravenous rt-PA); time-related data (time from stroke symptom onset to beginning of intervention (TI), procedural time, and time from symptom to the ending of procedure (TR)); technical information (whether balloon-mounted guiding catheter was used for flow arrest, concurrent intravenous thrombolysis, concurrent with other endovascular interventions, passing time of stent); and outcome variables (recanalization rate, symptomatic hemorrhage, procedure related complications, mortality within 3 months, and functional outcome).

The affected artery was classified as middle cerebral artery (MCA), terminal carotid artery (T-carotid) and vertebrobasilar artery. Recanalization was considered achieved when Thrombolysis in Myocardial Ischemia scale grade (TIMI) was 2 to 3 or when Thrombolysis in Cerebral Infarction grade (TICI) was $2 b$ to 3 . Technical failure was defined as an inability to access the clot with the device used. After endovascular intervention, the functional outcome was rated by using NIHSS and $\mathrm{mRS}$. When available, mRS status 3 months poststroke was used. A good outcome was defined as $\mathrm{mRS}$ 2 and less, or the NIHSS score had decreased by 10 points or more compared with pre-interventional NIHSS.

\section{RESULTS}

\section{Selection processing}

An initial search identified 634 abstracts. Next, 76 articles reporting information about mechanical thrombectomy using the Solitaire stent retrieval in the treatment of acute stroke were retrieved for further screening. Twenty articles were identified as possible candidates for evaluation, of which 7 were excluded for the following reasons: data overlapped with data in the other articles [3-5], insufficient data or case numbers [6-8], and an animal study [9]. The remaining 13 studies [3, 4, 10-21] were included for this review. There were no published randomized controlled trials of Solitaire thrombectomy compared to intravenous thrombolysis or other endovascular procedures. Two were retrospective comparative studies [10, 15], 2 were prospective case series $[12,19]$, and the rest were retrospective case series. The total number of patients included in this review was 262. Seven studies [3, 11, $13,14,17,18,21]$ presented individual raw data. The remaining 6 studies $[4,10,12,15,19,20]$ presented data as means or medians. Quantitative pooled metaanalysis was not performed due to heterogeneity of the study designs, inclusion criteria, and patient population.

\section{Patients' characteristics and Indication criteria for recanalization (Table 1)}

The mean age of patients varied from 58.9 to 76.4 years in the 13 studies. Of the 236 patients in 12 studies, there were 113 females. Mean initial NIHSS ranged from 14 to 21.4. Occluded segment included 149 MCAs (56.9\%), 59 T-carotids $(22.5 \%)$, and 54 vertebrobasilar arteries (20.6\%). Forty-one cases of 192 MCA or T-carotid occlusions (21.60\%) from 11 studies had tandem stenosis of proximal carotid artery.

Eleven studies identified the indications for recanalization therapy. However, the criteria were different for each study. The time window for anterior circulation ranged from 4.5 to 8 hours and posterior circulation was 24 hours. All studies used intravenous thrombolysis on the patients within 4.5 hours except for 1 case series that enrolled only patients with contraindication to intravenous thrombolysis. CT and/or MRI were used to evaluate the salvaging brain tissues and the presence of hemorrhage. NIHSS scores for the inclusion criteria varied from 4 to 12 .

\section{Time and Technical data (Table 2)}

TI was identified in 9 studies: the mean TI varied from 160 to 462.5 minutes. The mean time of the procedures ranged from 37 to 95.6 minutes in 10 studies, and the mean time for 8 of which were under 60 minutes. TR was 233 to 588 minutes in 10 studies.

Balloon-mounted guiding catheters were used in the anterior circulation for 6 of the 12 studies, but 6 studies were operated without balloon protection. Concurrent performance of intravenous thrombolysis was recorded in all 13 studies. One study had enrolled patients who were treated with only intra-arterial thrombectomy due to a contraindication of intravenous rt-PA. Bridging thrombolytic therapy combined with intravenous rt-PA or endovascular procedure for occlusions intractable to rt-PA were performed on 119 of 262 patients (45.4\%). Concurrent endovascular interventions, such as intraarterial thrombolysis, suction thrombectomy with Penumbra, and detachment of stent or balloon angioplasty before and after Solitaire thrombectomy, were attempted in 56 cases $(21 \%)$. Nine studies identified the passing time of the Solitaire stent. Passing time varied from 1 to 7 , and the mean passage rate ranged from 1.4 to 2.5 .

\section{Angiographic and Clinical results (Table 3)}

The success of recanalization was achieved in 235 
Jun Seok Koh, et al.

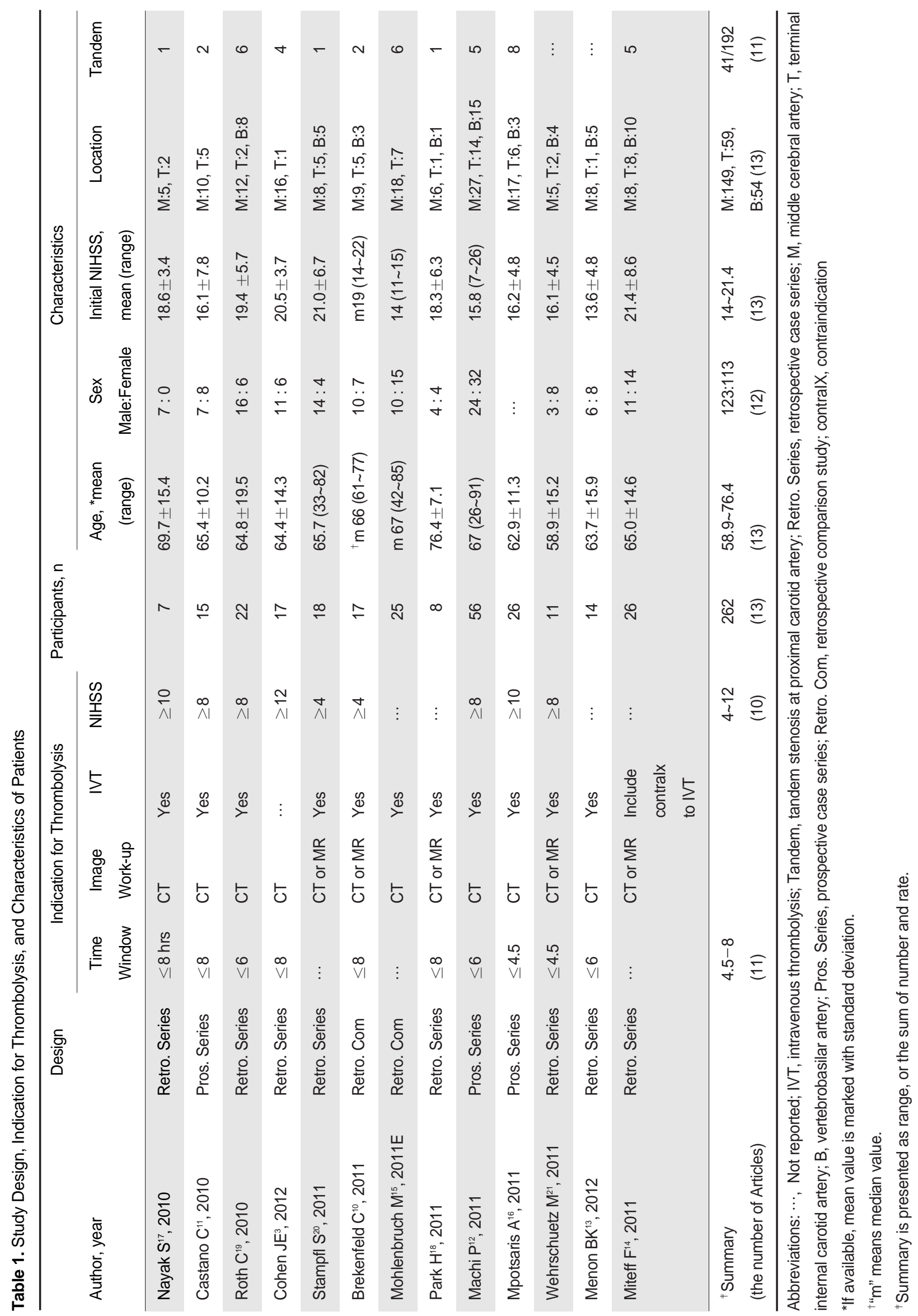




\section{Mechanical Thrombectomy with Solitaire Stent Retrieval}

cases $(89.7 \%)$ and the recanalization rate varied from $66.7 \%$ to $100 \%$ in all 13 studies. The reporting of NIHSS after procedure was identified in 10 studies. The time to record the post-procedural NIHSS varied from immediate to 3 months. 102 of 196 subjects $(52.0 \%)$ in 10 studies received a good outcome NIHSS rating. Symptomatic hemorrhagic complications developed in 16 out of 236 cases $(6.8 \%)$ in 12 studies. The overall mortality rate was $11.1 \%(29 / 262)$. In all studies except for 1 series, which achieved mRS at 1 month, mRS was assessed at 3 months after the procedure. The overall rate of a favorable mRS outcome was 50.8\% (133/262). Procedure-induced complications included 5 subarachnoid hemorrhages, 2 self-detachments of stent, 1 entanglement of stent, and 1 in-stent thrombosis.

\section{DISCUSSION}

This systematic review analyzed the studies had enrolled patients who were treated with mechanical thrombectomy using Solitaire stent retrieval for acute ischemic stroke, after being ineligible to receive intravenous rt-PA therapy or for which intravenous rtPA therapy had failed or be bridged with intravenous rt-PA. The present review demonstrated that mechanical thrombectomy with Solitaire stent retrieval provided a high recanalization rate and low procedurerelated complications. Favorable functional outcome was achieved in approximately half of the subjects.

The most of self-expanding stent for intracranial artery was originally designed as a supporting device in aneurysm coiling procedures. In 2006, an off-label use of the stent in acute stroke recanalization was discussed for the first time [22]. Initially, the self-expanding stent had been used in permanently deployment at occluded artery for recanalization. The concept of a stent placement was to entrap the thrombus between the stent and the vessel wall to restore antegrade blood flow by creating a channel inside the thrombus [23, 24]. This may be followed by thrombus dissolution via either endogenous or pharmacologic thrombolysis. However, permanent stent implantation requires a subsequent antiplatelet agent with an increased risk of intracranial hemorrhage. Another concern is the risk of in-stent stenosis. Despite limited data, several

Table 2. Time and Technique Data

\begin{tabular}{|c|c|c|c|c|c|c|c|}
\hline \multirow[b]{2}{*}{ Author, year } & \multicolumn{3}{|c|}{ Time, Minutes } & \multicolumn{4}{|c|}{ Techniques } \\
\hline & $\begin{array}{l}\text { TI, mean } \\
\text { (range) }\end{array}$ & $\begin{array}{l}\text { Procedure time, } \\
\text { mean (range) }\end{array}$ & $\begin{array}{l}\text { TR, mean } \\
\text { (range) }\end{array}$ & $\begin{array}{l}\text { Balloon } \\
\text { protection }\end{array}$ & $\begin{array}{l}\text { IVT, } \\
\mathrm{n}\end{array}$ & $\begin{array}{c}\text { Concurrent } \\
\text { intervention, } \mathrm{n}\end{array}$ & $\begin{array}{c}\text { Pass, } \\
\text { mean (range) }\end{array}$ \\
\hline Nayak S'7, 2010 & $160 \pm 83.1$ & $84.3 \pm 33.0$ & $307.1 \pm 106.7$ & No & 6 & 9 & $1.9 \pm 1$ \\
\hline Castano $C^{11}, 2010$ & $312.7 \pm 125.5$ & $57.9 \pm 26.0$ & $370.7 \pm 139.1$ & Yes & 7 & 0 & $\cdots$ \\
\hline Roth $C^{19}, 2010$ & $\cdots$ & $\cdots$ & $277 \pm 118$ & No & 13 & 10 & $1.77(1 \sim 4)$ \\
\hline Cohen $\mathrm{JE}^{3}, 2012$ & $254.1 \pm 104.5$ & $45.2 \pm 15.3$ & $299.3 \pm 113.7$ & Yes & 11 & 0 & $2.3 \pm 1.2$ \\
\hline Stampfl S ${ }^{20}, 2011$ & $240.9 \pm 71.4$ & $48.3 \pm 21.9$ & 377 (178 970) & No & 5 & 4 & $2.5 \pm 1.9$ \\
\hline Brekenfeld C ${ }^{10}, 2011$ & $\cdots$ & m52.5 (37.5 61) & $\cdots$ & Yes & 6 & 13 & $1.35(1 \sim 3)$ \\
\hline Mohlenbruch $\mathrm{M}^{15}, 2011 \mathrm{E}$ & $183(128 \sim 397)$ & 54 & 233 & No & 13 & 1 & $2(1 \sim 7)$ \\
\hline Park H ${ }^{18}, 2011$ & $197.1 \pm 95.0$ & $40.9 \pm 15.1$ & $238 \pm 106.1$ & Yes & 4 & 1 & $1.5 \pm 0.8$ \\
\hline Machi P'2, 2011 & 316 & 37 & 353 & Yes & 17 & 0 & $2(1-5)$ \\
\hline Mpotsaris $A^{16}, 2011$ & $\cdots$ & $\cdots$ & $328.6 \pm 149.2$ & $\cdots$ & 19 & 0 & $\cdots$ \\
\hline Wehrschuetz M²1, 2011 & $339.1 \pm 109.2$ & $\cdots$ & $\cdots$ & No & 11 & 0 & $2.3 \pm 1$ \\
\hline Menon BK ${ }^{13}, 2012$ & $\cdots$ & $84(26 \sim 164)^{*}(n=12)$ & $\cdots$ & No & 7 & 13 & $1 \sim 5$ \\
\hline Miteff $F^{14}, 2011$ & $462.5 \pm 582.8$ & $95.6 \pm 41.0$ & $558.2 \pm 577.8$ & Yes & 0 & 4 & $\cdots$ \\
\hline $\begin{array}{l}\text { Summary } \\
\text { (The number of articles) }\end{array}$ & $160 \sim 462.5(9)$ & $37 \sim 95.6(10)$ & $233 \sim 588(10)$ & $\begin{array}{l}\text { Yes: } 6 \text {, } \\
\text { No: } 6\end{array}$ & $\begin{array}{c}119 / 262 \\
45.4 \%\end{array}$ & $\begin{array}{c}55 / 262 \\
55 \%\end{array}$ & $1.4 \sim 2.5$ (10) \\
\hline
\end{tabular}

Abbreviations: TI, time from stroke symptom onset to beginning of intervention; TR, time from symptom to the ending of procedure; SD, standard deviation; IVT, intravenous thrombolysis

${ }^{*}$ Procedure time was not recorded in 2 patients. 


\section{Jun Seok Koh, et al.}

Table 3. Angiographic and Clinical Results

\begin{tabular}{|c|c|c|c|c|c|c|}
\hline Author, year & $\begin{array}{l}\text { Recanalization, } \\
\text { n (rate) }\end{array}$ & $\begin{array}{l}\text { Follow-up NIHSS } \\
\text { mean; } \\
\text { Good results, n; } \\
\text { Measuring time }\end{array}$ & $\begin{array}{c}\text { Symptomatic } \\
\qquad \mathrm{ICH}, \\
\mathrm{n}\end{array}$ & $\begin{array}{c}\text { Good } \\
\text { functional } \\
\text { results } \\
(\mathrm{mRS} \leq 2), n\end{array}$ & $\begin{array}{c}\text { Mortality, } \\
\mathrm{n}\end{array}$ & $\begin{array}{l}\text { Procedure- } \\
\text { induced } \\
\text { complication }\end{array}$ \\
\hline Nayak S ${ }^{17}, 2010$ & $7(100 \%)$ & $12 \pm 4.9 ; 3 / 7 ;$ immediate & $1 / 7$ & $4 / 7$ & $1 / 7$ & ${ }^{*} 1$ Self-detach \\
\hline Castano C ${ }^{11}, 2010$ & $15(100 \%)$ & $6.3 \pm 6.0 ; 7 / 14 ; 7$ days & $1 / 15$ & $8 / 15$ & $4 / 15$ & $1 \mathrm{SAH}$ \\
\hline Roth $\mathrm{C}^{19}, 2010$ & $20(90.9 \%)$ & NA; 14/22; discharge & $2 / 22$ & $11 / 22$ & $4 / 22$ & \\
\hline Cohen $\mathrm{JE}^{3}, 2012$ & $17(100 \%)$ & $5.1 \pm 3.2 ; 15 / 16 ; 7$ days & $2 / 17$ & $15 / 17$ & $1 / 17$ & \\
\hline Stampfl S ${ }^{20}, 2011$ & $12(66.7 \%)$ & NA & $3 / 18$ & $6 / 18$ & $3 / 18$ & \\
\hline Brekenfeld C ${ }^{10}, 2011$ & $16(94.1 \%)$ & m14 (6-20); NA; 1day & $0 / 17$ & $7 / 17$ & $0 / 17$ & \\
\hline Mohlenbruch $\mathrm{M}^{15}, 2011 \mathrm{E}$ & $22(88 \%)$ & 4 (2-9); NA; 7days & $3 / 25$ & $15 / 25$ & $2 / 25$ & \\
\hline Park H ${ }^{18}, 2011$ & $8(100 \%)$ & $12.3 \pm 7.7 ; 1 / 8 ;$ immediate & $0 / 8$ & $4 / 8$ & $0 / 8$ & \\
\hline Machi P $P^{12}, 2011$ & $50(89.3 \%)$ & NA; 30/56; discharge & $1 / 56$ & $26 / 56$ & $4 / 56$ & $2 \mathrm{SAH}$ \\
\hline Mpotsaris $A^{16}, 2011$ & $23(88.5 \%)$ & $7.4 \pm 6.4 ; 11 / 26 ;$ discharge & $\cdots$ & $10 / 26$ & $2 / 26$ & \\
\hline Wehrschuetz M²1, 2011 & $8(72.7 \%)$ & $10 \pm 7 ; 2 / 11 ;$ immediate & $0 / 11$ & $8 / 11$ & $1 / 11$ & \\
\hline Menon $\mathrm{BK}^{13}, 2012$ & $12(70.6 \%)$ & $8.8 \pm 7.9 ; 3 / 12 ; 1$ day & $1 / 14$ & $8 / 14$ & $2 / 14$ & 1 In-stent thrombosis, $1 \mathrm{SAH}$ \\
\hline Miteff $F^{14}, 2011$ & $25(96.2 \%)$ & NA; 16/20; 3months & $2 / 26$ & $11 / 26$ & $5 / 26$ & $\begin{array}{c}1 \text { Self-detach, } \\
{ }^{\dagger} 1 \text { entanglement, } 1 \mathrm{SAH}\end{array}$ \\
\hline $\begin{array}{l}\text { Summary } \\
\text { (the number of articles) }\end{array}$ & $\begin{array}{c}235 / 262 \\
89.7 \%\end{array}$ & $\begin{array}{c}102 / 196 \\
52.0 \%(10)\end{array}$ & $\begin{array}{c}16 / 236 \\
6.8 \%(12)\end{array}$ & $\begin{array}{c}133 / 262 \\
47.7 \%\end{array}$ & $\begin{array}{c}29 / 262 \\
11.1 \%\end{array}$ & \\
\hline
\end{tabular}

Abbreviations: $\mathrm{ICH}$, intracerebral hemorrhage; $\mathrm{SAH}$, subarachnoid hemorrhage; NA, not applicable

*Self-detach means an unanticipated self-detach of stent during procedure

${ }^{\dagger}$ Entanglement means the entanglement of stent during procedure

retrospective case series have demonstrated thromboembolic complications and fatal intra-cerebral hemorrhage $[25,26]$. The next technique using a stent in treatment for acute stroke was the temporary endovascular bypass. A partial deployment of a selfexpandable stent (Enterprise stent, Codman, Raynham, MA, U.S.A.) has resulted in an immediate recanalization of occluded cerebral artery that was refractory to intravenous or intra-arterial fibrolytic agents [27, 28]. This technique had the advantage of avoiding antiplatelet therapy or in-stent stenosis, compared with the permanent implant of the stent. The last presented technique using a self-expanded stent is the retrieval of the stent, which allows for the temporary recanalization as well as the extraction of the thrombus from cerebral circulation.

There have been several reports about Solitaire thrombectomy since the first case was reported in 2009 [29]. The Solitaire is a self-expanding stent initially designed for bridging the neck of aneurysms that is retrievable even after complete deployment for adjust- ment and superior placement, if not detached. Its openslit, closed-cell design gives an optimal radial force with good kink resistance and maximizes the opportunity for trapping the clot [30]. These properties have led to its use in acute stoke, in which the thrombus within the cerebral vessels is trapped within the struts of the stent and pulled out of the body. Because the Solitaire stent was designed for neck remodeling of aneurysm coiling, the delivery and deployment of this stent can be handled easily by a single operator, and the Solitaire can be delivered through a standard 0.021 or 0.027 inch (internal diameter) microcatheter. The use of a microcatheter for the delivery of the Solitaire stent allows easier navigation and safer manipulation because of its flexibility, and may reduce the chance of a thrombolysis failure in difficult cases, such as elderly patients with tortuous vessels. The merit of the Solitaire stent is that its simplicity of approach to the intracranial artery may make thrombolytic procedures easier. Compared with the MERCI (2.4 Fr) and Penumbra systems (varied from 2.8 Fr to 4.1 Fr), the Solitaire 
stent can be delivered by the microcatheter with the smallest distal outer diameter (Rebar ${ }^{\mathrm{TM}} 18$ microcatheter, ev3; $2.3 \mathrm{Fr}$ ).

Theoretically, another advantage of the Solitaire stent is recanalization time-saving. In a study that compared the clot retrieval with Solitaire stent and other endovascular procedures, including mechanical thrombectomy and intra-arterial thrombolysis [10], the advantage of the Solitaire thrombectomy device was in reducing the time to recanalization in a multimodal approach to endovascular stroke treatment. In our review, 8 of the 10 studies have revealed that the mean time of the total procedure was less than 60 minutes.

Intravenous rt-PA is the quickest way to initiate thrombolysis for acute ischemic stroke. However, thrombus within large vessel is relatively resistant to rtPA and IV thrombolysis alone does not result in rapid recanalization [1, 2, 31]. Compared with intravenous rtPA, intra-arterial endovascular therapy has several theoretic advantages, including site specificity, longer treatment windows, and higher recanalization rates. However, the disadvantage of endovascular therapy is the lag time during which the procedure is initiated. To avoid low recanalization rates by intravenous rt-PA or delayed reopening by endovascular procedure, a bridging approach of both methods has been tried to enhance a favorable clinical outcome.

Intra-arterial thrombolysis permits a smaller dose of fibrinolytic agent to reach a higher local concentration than intravenous administration and ideally allows more complete recanalization with lower doses of thrombolytic. This method's chief disadvantage, however, is the lag time during which fibrinolysis is initiated and proceeded. The mean procedure duration was 2.1 hours in the PROACT II trials. Particularly in patients with long-segment artery occlusion, vessel recanalization with intra-arterial thrombolysis alone is often unsuccessful in spite of the larger volume of fibrinolytic agent. Moreover, the recanalization rate was inferior to that of mechanical thrombectomy. Therefore, an endovascular approach for acute stroke is shifting from intra-arterial thrombolysis to mechanical thrombectomy.

The best way to treat an acute ischemic stroke is to remove the occluding thrombi by using an aspiration or capture of the thrombi before the brain tissues are damaged by ischemia. In contrast, pharmacologic fibrinolysis is a long procedure and is often ineffective. Because these theoretical and practical benefits of mechanical thrombolysis override the limitations with pharmacological thrombolysis, various mechanical devices have been introduced, including wires, coils, balloons, and capture or aspiration devices.

Despite a strong demand for mechanical thrombectomy based on theoretical assumption, there was a little evidence that legitimizes the use of various devices for endovascular thrombectomy. At present, only two devices were approved by FDA. The MERCI retrievers are a family of corkscrew-shaped products designed to remove blood clots from the cerebral arteries. The most recent data of the Multi-MERCI trial, a study with approximately the same inclusion criteria as the previous study but with treatment within 8 hours, was released [32]. One hundred and sixty-four patients were enrolled, and 131 were initially treated with the newer generation of MERCI L5 retriever. Recanalization by pure mechanical thrombectomy was $57.3 \%$, whereas a recanalization rate of $68 \%$ was achieved after additional intra-arterial thrombolysis. More importantly, the clinical outcomes after 3 months were significantly improved. Mean procedure time for recanalization of MCA occlusion was approximately100 minutes [33]. The Penumbra system that is designed for continuous aspiration thrombectomy for large arterial occlusion is only an aspiration device indicated for revascularization in acute ischemic stroke. The Penumbra Pivotal Stroke Trial [34] was a prospective, multicenter, single-arm study that assessed the safety and efficacy of the penumbra system with the largest number of subjects [34]. $81.6 \%$ of the treated vessels were successfully recanalized. 14 patients $(11.2 \%)$ were found to have symptomatic intracranial hemorrhage and all cause mortality was $32.8 \%$ within 90 days. A quarter of the patients achieved a favorable functional outcome.

In present study, the recanalization rate of the Solitaire stent (89.7\%) was superior to the recanalization rate in the Penumbra Pivotal Stroke trial (81.6\%) and the Multi-MERCI trial (69.5\%). In the MultiMERCI trial, the rate of symptomatic cerebral hemorrhage, mortality, and favorable outcome were $10 \%, 34 \%$, and $36 \%$ respectively. The Penumbra Pivot trial revealed that the rate of symptomatic cerebral hemorrhage, mortality, and favorable outcome were $11.2 \%, 32.8 \%$, and $20 \%$ respectively. When the results of our review were compared with the results of Penumbra and MERCI trials, Solitaire stent appeared to have more favorable clinical outcomes. However, the present study has been limited by the inclusion of studies with the suboptimal mythological quality, heterogeneous cohort, and nonrandomized data. Therefore, our results should not be compared with 
other single trials using prospective and randomized designs.

Currently available neurothrombectomy devices offer intriguing treatment options in patients with acute ischemic stroke, although a paucity of high-quality research exists. Besides MERCI and Penumbra devices, many articles have reported the use and results of off-label devices, including snare, laser devices, clot emulsification system with ultrasound, and thromboapsiration devices, for acute ischemic stroke. However, the clinical application is limited because of weak evidence in these studies. The last review that summarize the neurothrombectomy devices for the treatment of acute stroke showed that almost all studies using off-label devices had small cohorts of under 60 [35].

The first clinical trial to assess the Solitaire stent was the ReFlow study that investigated whether the application of Solitaire stent retrieval is a safe and feasible method for interventional recanalization of large vessels with favorable patient outcomes in acute stroke therapy, and this research has been completed [19]. Currently, 4 ongoing studies evaluating the Solitaire stent in acute stroke are listed in Clinicaltrial.gov. STAR (Solitaire FR Thrombectomy for Acute Revascularisation, NCT01327989) is a prospective cohort design, and will evaluate the safety and efficacy of the Solitaire device in subjects requiring mechanical thrombectomy. Of note, the SWIFT (Solitaire FR with the Intention for Thrombectomy, NCT01054560) study will be the first to evaluate the comparative effectiveness of 2 different technologies, the Solitaire FR and the MERCI Retriever, by using a prospective, randomized method in patients with acute ischemic stroke. EXTEND-IA (Extending the Time for Thrombolysis in Emergency Neurological Deficits - Intra-Arterial, NCT01492725) is a prospective, randomized, openlabel, blinded endpoint design, and has two arms: an intravenous rt-PA with Solitaire thrombectomy and a standard intravenous rt-PA. The THRACE (Trial and Cost Effectiveness Evaluation of Intra-arterial Thrombectomy in Acute Ischemic Stroke, NCT01062698) study will compare intravenous thrombolysis with thrombectomy procedures using the MERCI retriever, Penumbra thromboaspiration system, Catch device, and the Solitaire on approximately 480 patients.

A couple of limitations of our analysis should be noted. As referred to earlier, this reviewed studies lacked in well-designed research. Our systematic review included only retrospective case series and case series with nonrandomized data. These studies are likely to have significant publication bias because negative findings are frequently not published. The other disadvantage is that the subjects were heterogeneous in cohort and reporting methods. Thromboembolic complication, one of the critical complications during endovascular procedures, was not commented in almost all the articles. Nevertheless, the merit of this systematic review is that the findings of emerging data can help guide clinicians in choosing the most appropriate treatment for acute ischemic stroke, as well as encourage more rigorous prospective study designs with large cohorts in the future.

In summary, we have demonstrated that, overall, mechanical thrombectomy using a Solitaire stent in acute ischemic stroke was effective in recanalizing occluded arteries, and this was not inferior to other neurothrombectomy devices or pharmacologic fibrinolysis in clinical results. Future studies should attempt to assess larger and randomized cohorts, and design prospective and case-controlled studies.

\section{References}

1. Rha JH, Saver JL. The impact of recanalization on ischemic stroke outcome: a meta-analysis. Stroke 2007;38:967-973

2. Furlan A, Higashida R, Wechsler L, Gent M, Rowley H, Kase C, et al. Intra-arterial prourokinase for acute ischemic stroke. The PROACT II study: a randomized controlled trial. Prolyse in acute cerebral thromboembolism. JAMA 1999;282:2003-2011

3. Cohen JE, Gomori JM, Leker RR, Moscovici S, RamirezDenoriega F, Itshayek E. Recanalization with stent-based mechanical thrombectomy in anterior circulation major ischemic stroke. $J$ Clin Neurosci 2012;19:39-43

4. Costalat V, Machi P, Lobotesis K, Maldonado I, Vendrell JF, Riquelme $\mathrm{C}$, et al. Rescue, combined, and stand-alone thrombectomy in the management of large vessel occlusion stroke using the Solitaire device: a prospective 50-patient single-center study: timing, safety, and efficacy. Stroke 2011;42:1929-1935

5. Cohen JE, Leker RR, Moscovici S, Attia M, Itshayek E. Stentbased mechanical thrombectomy in acute basilar artery occlusion. J Clin Neurosci 2011;18:1718-1720

6. Seifert M, Ahlbrecht A, Dohmen C, Spuentrup E, MoellerHartmann W. Combined interventional stroke therapy using intracranial stent and local intraarterial thrombolysis (LIT). Neuroradiology 2011;53:273-282

7. Fesl G, Wiesmann M, Patzig M, Holtmannspoetter M, Pfefferkorn T, Dichgans M, et al. Endovascular mechanical recanalisation of acute carotid-T occlusions: a single-center retrospective analysis. Cardiovasc Intervent Radiol 2011;34:280-286

8. Castano C, Serena J, Davalos A. Use of the new Solitaire (TM) $\mathrm{AB}$ device for mechanical thrombectomy when Merci clot retriever has failed to remove the clot. A case report. Interv Neuroradiol 2009;15:209-214

9. Mordasini P, Frabetti N, Gralla J, Schroth G, Fischer U, Arnold $\mathrm{M}$, et al. In vivo evaluation of the first dedicated combined flow- 


\section{Mechanical Thrombectomy with Solitaire Stent Retrieval}

restoration and mechanical thrombectomy device in a swine model of acute vessel occlusion. AJNR Am J Neuroradiol 2011;32:294-300

10. Brekenfeld C, Schroth G, Mordasini P, Fischer U, Mono ML, Weck A, et al. Impact of retrievable stents on acute ischemic stroke treatment. AJNR Am J Neuroradiol 2011;32:1269-1273

11. Castano C, Dorado L, Guerrero C, Millan M, Gomis M, Perez de la Ossa N, et al. Mechanical thrombectomy with the Solitaire AB device in large artery occlusions of the anterior circulation: a pilot study. Stroke 2010;41:1836-1840

12. Machi P, Costalat V, Lobotesis K, Lima Maldonado I, Vendrell JF, Riquelme C, et al. Solitaire FR thrombectomy system: immediate results in 56 consecutive acute ischemic stroke patients. J Neurointerv Surg 2012;4:62-66

13. Menon BK, Kochar P, Ah-Seng A, Almekhlafi MA, Modi J, Wong $\mathrm{JH}$, et al. Initial experience with a self-expanding retrievable stent for recanalization of large vessel occlusions in acute ischemic stroke. Neuroradiology 2012;54:147-154

14. Miteff F, Faulder KC, Goh AC, Steinfort BS, Sue C, Harrington TJ. Mechanical thrombectomy with a self-expanding retrievable intracranial stent (Solitaire AB): experience in 26 patients with acute cerebral artery occlusion. AJNR Am J Neuroradiol 2011;32:1078-1081

15. Mohlenbruch M, Seifert M, Okulla T, Wullner U, Hadizadeh DR, Nelles M, et al. Mechanical thrombectomy compared to localintraarterial thrombolysis in carotid $t$ and middle cerebral artery occlusions : a single center experience. Clin Neuroradiol Epub 2011, oct

16. Mpotsaris A, Bussmeyer M, Loehr C, Oelerich M, Buchner H, Weber W. Mechanical thrombectomy in severe acute stroke: preliminary results of the Solitaire stent. J Neurol Neurosurg Psychiatry 2012;83:117-118

17. Nayak S, Ladurner G, Killer M. Treatment of acute middle cerebral artery occlusion with a Solitaire AB stent: preliminary experience. Br J Radiol 2010;83:1017-1022

18. Park H, Hwang GJ, Jin SC, Jung CK, Bang JS, Han MK, et al. A retrieval thrombectomy technique with the Solitaire stent in a large cerebral artery occlusion. Acta Neurochir (Wien) 2011;153:1625-1631

19. Roth C, Papanagiotou P, Behnke S, Walter S, Haass A, Becker C, et al. Stent-assisted mechanical recanalization for treatment of acute intracerebral artery occlusions. Stroke 2010;41:2559-2567

20. Stampfl S, Hartmann M, Ringleb PA, Haehnel S, Bendszus M, Rohde S. Stent placement for flow restoration in acute ischemic stroke: a single-center experience with the Solitaire stent system. AJNR Am J Neuroradiol 2011;32:1245-1248

21. Wehrschuetz M, Wehrschuetz E, Augustin M, Niederkorn K, Deutschmann H, Ebner F. Early single center experience with the Solitaire thrombectomy device for the treatment of acute ischemic stroke. Interv Neuroradiol 2011;17:235-240

22. Fitzsimmons BF, Becske T, Nelson PK. Rapid stent-supported revascularization in acute ischemic stroke. AJNR Am J Neuroradiol 2006;27:1132-1134

23. Levy EI, Ecker RD, Hanel RA, Sauvageau E, Wehman JC, Guterman LR, et al. Acute M2 bifurcation stenting for cerebral infarction: lessons learned from the heart: Technical case report. Neurosurgery 2006;58:E588

24. Levy EI, Ecker RD, Horowitz MB, Gupta R, Hanel RA, Sauvageau E, et al. Stent-assisted intracranial recanalization for acute stroke: early results. Neurosurgery 2006;58:458-463

25. Levy EI, Mehta R, Gupta R, Hanel RA, Chamczuk AJ, Fiorella D, et al. Self-expanding stents for recanalization of acute cerebrovascular occlusions. AJNR Am J Neuroradiol 2007;28:816-822

26. Zaidat OO, Wolfe T, Hussain SI, Lynch JR, Gupta R, Delap J, et al. Interventional acute ischemic stroke therapy with intracranial self-expanding stent. Stroke 2008;39:2392-2395

27. Suh SH, Kim BM, Roh HG, Lee KY, Park SI, Kim DI, et al. Selfexpanding stent for recanalization of acute embolic or dissecting intracranial artery occlusion. AJNR Am J Neuroradiol 2010;31: 459-463

28. Suh SH, Lee KY, Hong CK, Kim BM, Kim CH, Chung TS, et al. Temporary stenting and retrieval of the self-expandable, intracranial stent in acute middle cerebral artery occlusion. Neuroradiology 2009;51:541-544

29. Liebig T, Lockau H, Dorn F, Miloslavski E, Henkes H. Stenting of thromboembolic stroke using a fully retrievable self expanding stent. In: Proceedings of the ABC-WIN Meeting of the World Federation of Interventional and Therapeutic Neuroradiology, 1116 January 2009, Val d'Isere, France.

30. Klisch J, Eger C, Sychra V, Strasilla C, Basche S, Weber J. Stentassisted coil embolization of posterior circulation aneurysms using Solitaire AB: preliminary experience. Neurosurgery 2009;65:258266; discussion 266

31. Lindsberg PJ, Mattle HP. Therapy of basilar artery occlusion: a systematic analysis comparing intra-arterial and intravenous thrombolysis. Stroke 2006;37:922-928

32. Smith WS, Sung G, Saver J, Budzik R, Duckwiler G, Liebeskind DS, et al. Mechanical thrombectomy for acute ischemic stroke: final results of the Multi MERCI trial. Stroke 2008;39:1205-1212

33. Shi ZS, Loh Y, Walker G, Duckwiler GR. Clinical outcomes in middle cerebral artery trunk occlusions versus secondary division occlusions after mechanical thrombectomy: pooled analysis of the mechanical embolus removal in cerebral ischemia (MERCI) and Multi MERCI trials. Stroke 2010;41:953-960

34. The penumbra pivotal stroke trial: safety and effectiveness of a new generation of mechanical devices for clot removal in intracranial large vessel occlusive disease. Stroke 2009;40:2761-2768

35. Baker WL, Colby JA, Tongbram V, Talati R, Silverman IE, White $\mathrm{CM}$, et al. Neurothrombectomy devices for the treatment of acute ischemic stroke: state of the evidence. Ann Intern Med 2011;154: 243-252 